\title{
Effect of Surface Layer Structural-Phase Modification on Tribological and Strength Properties of a TiC-(Ni-Cr) Metal Ceramic Alloy
}

\author{
Bao-Hai Yu' ${ }^{1}$ V. E. Ovcharenko ${ }^{2,3}$ - K. V. Ivanov ${ }^{3}$ A. A. Mokhovikov ${ }^{2}$ Yan-Hui Zhao ${ }^{1}$
}

Received: 7 July 2017 / Revised: 3 August 2017 / Published online: 22 September 2017

(C) The Chinese Society for Metals and Springer-Verlag GmbH Germany 2017

\begin{abstract}
This paper reports $\mathrm{TiC}-(\mathrm{Ni}-\mathrm{Cr})$ metal ceramic alloy (ratio of components 50:50) with nanoscaled components formed in the surface layer and smoothly transformed into the initial inner structure throughout the material under pulsed electron irradiation of the alloy surface. Principal changes in the surface layer are ascribed to the formation of gradient structure leading to the increase in wear resistance of the surface layer, drop of friction coefficient and improvement of specimen bending resistance when stressing on the irradiated surface side. The above changes of tribological and strength properties in the surface layer under pulsed electron irradiation become more apparent with increasing atomic mass of a plasma-forming inert gas.
\end{abstract}

KEY WORDS: Metal ceramic alloy; Particle-reinforced composite; Interphase boundaries; Tribological behavior; Bending strength; Electron beam treatment

\section{Introduction}

Metal ceramic alloys based on highly rigid and heat-resistant chemical compounds (carbides, nitrides, carbonitrides and oxides) and metallic binding agents are up-todate functional composite materials used in service environment of metal-cutting tools: shock loading, dry friction, abrasive wear and higher temperatures [1-4]. According to the world market of conventional metal ceramic instruments, it has been revealed that approximately $67 \%$ of

Available online at http://link.springer.com/journal/40195

Bao-Hai Yu

bhyu@imr.ac.cn

1 Institute of Metal Research, Chinese Academy of Sciences, Shenyang 110016, China

2 Tomsk Polytechnic University, Tomsk 634050, Russia

3 Institute of Strength Physics and Materials Science, Siberian Branch of the Russian Academy of Sciences, Tomsk 634021, Russia metal ceramic alloys are applied in metal-cutting tools, $13 \%$ in drilling and rock-destructing machines, $11 \%$ in woodworking and $9 \%$ in chipless processing of engineering materials. The trends in production of metal ceramic alloys indicate that the world's consumption of conventional metal ceramic instruments has doubled over the last 5 years.

Improvement of metal-cutting tools to gain in performance of processing up-to-date metallic alloys aims primarily at heightening durability of metal ceramic cutting inserts in conditions of high-speed cutting. In metal cutting, durability of cutting inserts depends on a complex of physical and strength properties of surface layers with the thickness up to $200 \mu \mathrm{m}$ [5-8]. As indicated in theoretical and experimental studies, surface layer durability of inserts can be improved by structural-phase modification, arising as a result of a multi-level structural-phase state with a nanoscale component in the surface layer [9-16].

The specific objective of this study was to examine the influence of surface layer structural-phase modification in $50 \% \mathrm{TiC} / 50 \%(\mathrm{Ni}-\mathrm{Cr})$ metal ceramic alloy under pulsed electron ion plasma irradiation on wear and bending 
resistance of the surface layer of the alloy specimens when stressing on the modified surface.

\section{Experimental}

Specimens of $\mathrm{TiC} /(\mathrm{Ni}-\mathrm{Cr})$ metal ceramic alloy (component ratio is 50:50) were used in the investigation. Surface layer structural-phase modification of the specimens was implemented by using pulsed electron irradiation [17-21] in argon, krypton and xenon plasmas with variations in atomic weights and ionizing energy (Table 1).

After completion of electron plasma irradiation, structural-phase state of the surface layer in metal ceramic alloy specimens was explored by transmission microscopy (TEM, JEM-2100). Thin foils for TEM taken from cross to the surface layer specimen sections were made with an ion slicer (Jeol EM-09100IS) at accelerating voltage $8 \mathrm{kV}$ and ion beam incidence angle $4^{\circ}$ (Fig. 1).

Wear resistance of the surface layer and friction coefficient on the modified surface of alloy specimens were measured in a tribometer (CSEM Tribometer High Temperature S/N 07-142) according to the scheme specimen rotation at a stationary counterbody. Diamond cone load was $5 \mathrm{~N}$, and the finite number of specimen rotations is 2500. Applying micrometric system micromeasure system STIL, friction forces were recorded uninterruptedly and translated further into absolute values of friction coefficient. A cross-section profile of a groove cut with a diamond counterbody on the surface of metal ceramic specimens was measured by 3D-profilometer MICRO MEASURE 3D Station, and the depth of cutting and cross section were numerically determined.

Three-point bending tests of metal ceramic alloy specimens were carried out with an Instron-3369 according to standard ISO 3327-82 when stressing alloy specimens uninterruptedly at a speed of $0.2 \mathrm{~mm} / \mathrm{min}$.

\section{Results and Discussion}

Figure 2 shows the TEM microstructure of the metal ceramic alloy in the as-received state. One can see coarse titanium carbide particles from 3 to $7 \mu \mathrm{m}$ in size and $\mathrm{Ni}-\mathrm{Cr}$

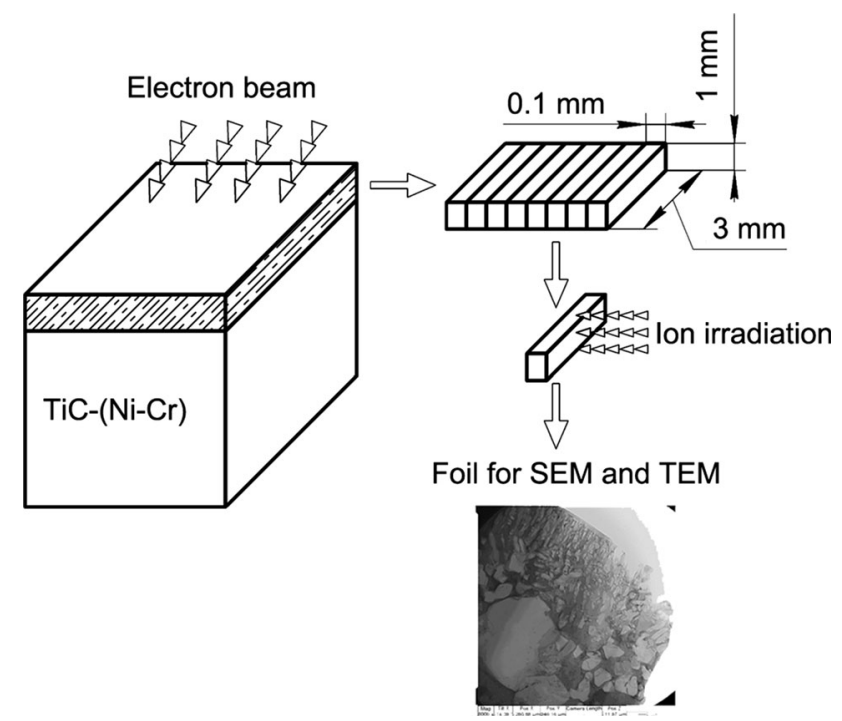

Fig. 1 Diagram of specimen preparation for TEM analysis microstructure of the surface layer (cross section)

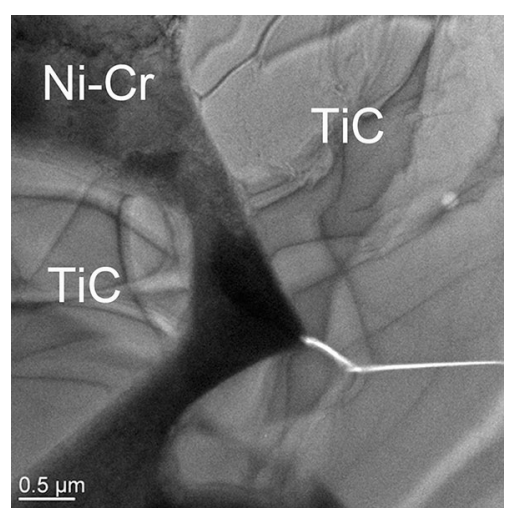

Fig. 2 TEM image of TiC-(Ni-Cr) metal ceramic alloy microstructure in the initial state

metallic binding. Pulsed electron ion plasma irradiation of the alloy results in significant transformations in the surface layer microstructure. Investigation of the structural features of the alloy surface layer irradiated in plasmas of the all used inert gases revealed similarity in their structural heterogeneity but difference in the quantitative parameters of the structure. All of the microstructures involve the definite sublayers with characteristic microstructures in each sublayer (Fig. 3). The top sublayer

Table 1 Pulsed electron irradiation in argon, krypton and xenon plasmas differing in atomic weights and ionizing energy

\begin{tabular}{lcc}
\hline Plasma-forming gas & Atomic weight $(\mathrm{g} / \mathrm{mol})$ & Ionizing energy $(\mathrm{kJ} / \mathrm{mol})$ \\
\hline $\mathrm{Ar}$ & 39.948 & 1519.6 \\
$\mathrm{Kr}$ & 83.798 & 1350.0 \\
$\mathrm{Xe}$ & 131.29 & 1170.0 \\
\hline
\end{tabular}




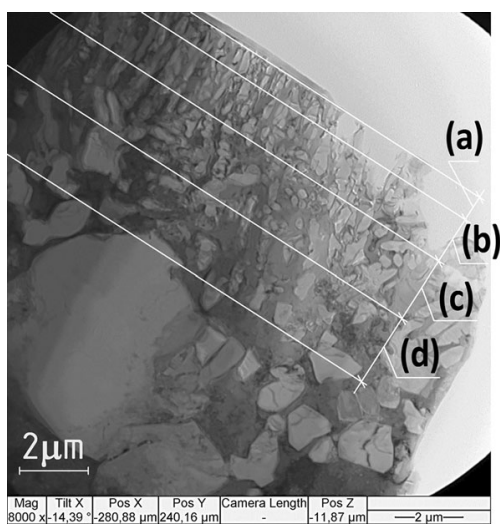

Fig. 3 General view of TiC-(Ni-Cr) metal ceramic alloy surface layer microstructure (irradiation in argon plasma at electron beam energy density $60 \mathrm{~J} / \mathrm{cm}^{2}$, irradiation pulse duration $150 \mu \mathrm{s}, 15$ irradiation pulses (TEM)): a the structure of column-formed carbide particles as a result of high-speed crystallization of top surface layer melt; b metal ceramics with nanoscaled carbide particles; $c$ the bottom sublayer with submicro- and microscaled carbide particles; $d$ transition area to the initial structure of metal ceramic alloy

has nanosized structure with column configuration of ceramic particles oriented perpendicularly to the specimen surface. The next intermediate sublayer consists of submicron-sized titanium carbide particles differently oriented in the metal binder. The next bottom sublayer has dendrite structure. Then, the structure gradually transforms to the initial structure of the alloy.

The thickness of metal ceramic alloy structure modification after pulsed electron irradiation depends on energy, pulse duration and the type of plasma gas. The dependences of the thickness of the modified surface layer on the pulse duration obtained in 40 and $60 \mathrm{~J} / \mathrm{cm}^{2}$ energies and $\mathrm{Ar}, \mathrm{Kr}$ and $\mathrm{Xe}$ plasmas are represented in Fig. 4.

Increase in the pulse duration causes the increases in both thickness of the top sublayer with nanosized column structure and total thickness of the modified surface layer. The only exception takes place in the case of irradiation in xenon plasma with the pulse duration of $200 \mu$ s when the thickness of the layer decreases (Fig. 4c). The decrease may be related to the increase in the fraction of metal binder and, consequently, to the enhancement of heat sink to the bulk of the alloy. The thickness of the top sublayer does not depend on the type of plasma gas or energy density in the electron beam. The total thickness of the modified layer weakly depends on the energy density in the case of argon plasma. The dependence becomes more pronounced after irradiation in krypton plasma and further expressed in the case of xenon. The maximal thickness of the modified surface layer at electron beam energy density of $60 \mathrm{~J} / \mathrm{cm}^{2}$ varies from $35 \mu \mathrm{m}$ (argon plasma) to $40 \mu \mathrm{m}$ (krypton plasma) and $47 \mu \mathrm{m}$ (xenon plasma).

Modification of the surface layer structure significantly has an effect on wear resistance and strength of metal ceramic alloy. Figure 5 represents the dependence of the groove depth cut with a diamond cone on the surface of irradiated composite samples and the friction coefficient value on the density of electron beam energy under pulsed electron irradiation in argon, krypton and xenon plasmas.

It can be concluded that pulsed electron beam irradiation for all used gases improves wear resistance of a metal ceramic alloy. The higher electron beam density is, the more wear resistant is the surface layer of a composite. The plasma gas is relevant for the level of surface layer wear resistance. The samples irradiated in Xe plasma exhibit the highest wear resistance at the energy density of $60 \mathrm{~J} / \mathrm{cm}^{2}$. The wear resistance decreases when irradiation occurs in $\mathrm{Kr}$ plasma and further decreases after $\mathrm{Ar}$ plasma irradiation.

The common feature of friction coefficient values is their stability when changing the density of electron beam energy and the pulse duration. This emphasizes the similarity of the structures of the top sublayers when the densities of energy and pulse duration are changed.

The dependencies of wear resistance and friction coefficient available on the energy density of the electron beam when irradiated in $\mathrm{Ar}, \mathrm{Kr}$ and $\mathrm{Xe}$ plasmas are in a good agreement with those of the total modified surface thickness and the thickness of the top sublayer with columnar structure on the pulse duration (Fig. 4). One can see that the wear resistance is enhanced with the increase in the
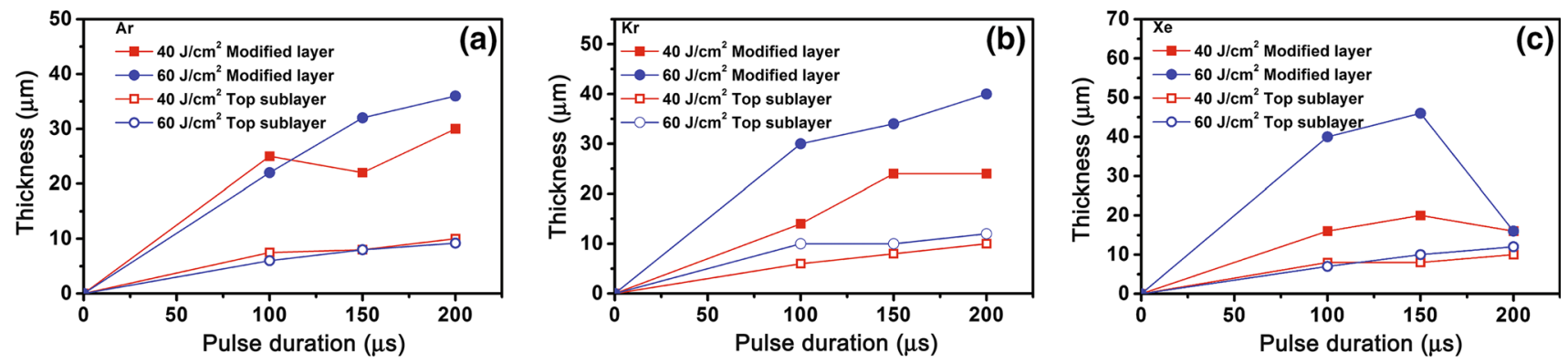

Fig. 4 Thickness of the modified layer under pulsed electron irradiation of its surface in argon, krypton and xenon plasmas vs irradiation pulse duration at electron beam energy densities 40 and $60 \mathrm{~J} / \mathrm{cm}^{2}$ (15 irradiation pulses) 

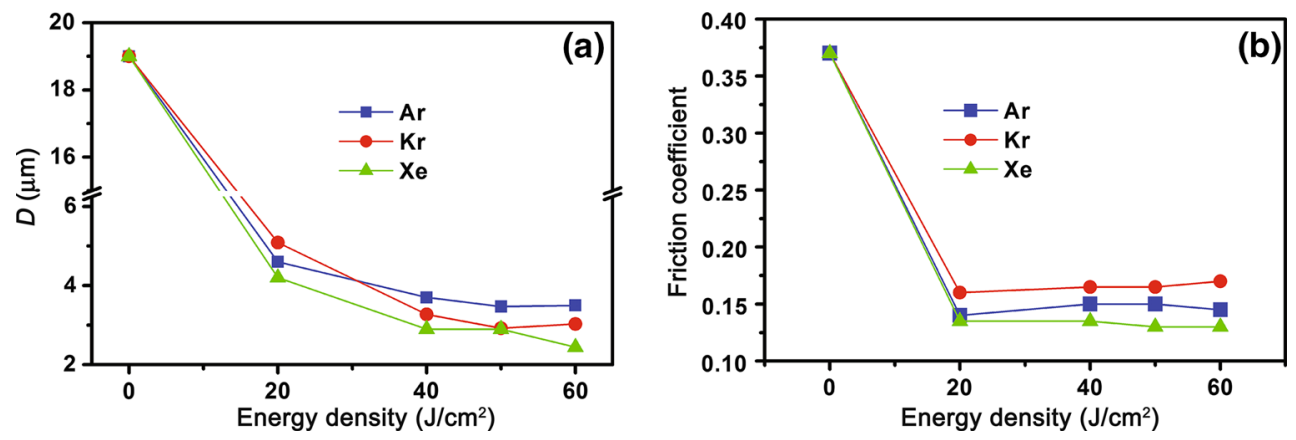

Fig. 5 Wear rate cut $\mathbf{a}$ by the diamond counterbody in the surface layer of metal ceramic alloy and value of friction coefficient $\mathbf{b}$ on the surface of alloy specimens after pulsed electron irradiation in argon, krypton and xenon plasmas vs electron beam energy density at pulse duration $150 \mu$ s (15 irradiation pulses)
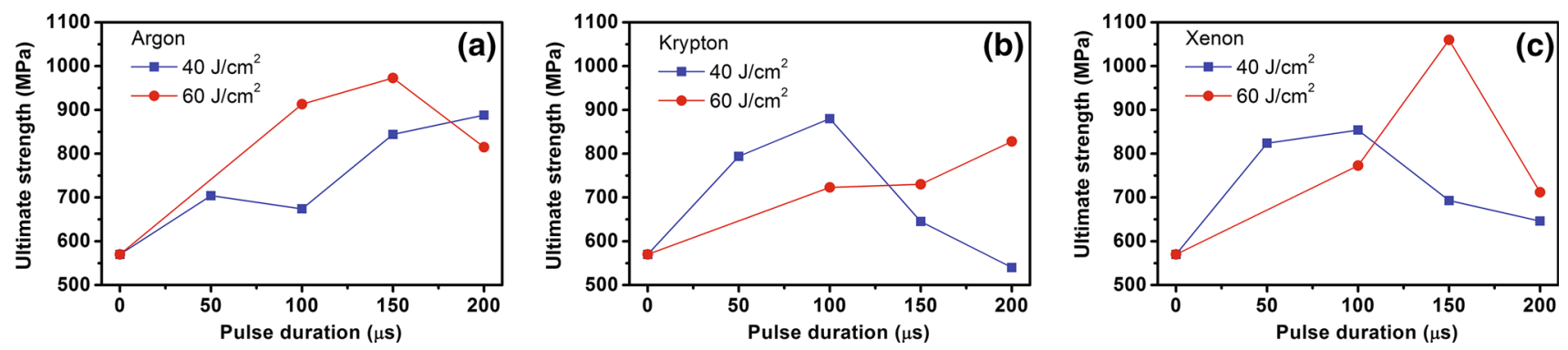

Fig. 6 Ultimate strength under bending when loading on the irradiated surface after pulsed electron irradiation in argon a, krypton $\mathbf{b}$, xenon c versus electron irradiation pulse duration for electron beam energy density 40 and $60 \mathrm{~J} / \mathrm{cm}^{2}$ (15 irradiation pulses)

thickness of the layer and the friction coefficient decreases with the increase in the thickness of the top sublayer.

The dependencies of the ultimate bending strength on the irradiation pulse duration in argon, krypton and xenon plasmas for the energy densities of 40 and $60 \mathrm{~J} / \mathrm{cm}^{2}$ and 15 pulses are shown in Fig. 6. It is evident from Fig. 6 that refining the structure of the surface layer by electron irradiation in inert gases plasma increases the bending strength. As pulse duration and energy density increase, the modified depth and volume fraction of nanosized particles increase in the modified layer. The compressive strength and bending strength under are all increased when the load is applied from the irradiated side (Figs. 4 and 6). This influence is most significant at the electron beam energy density of $60 \mathrm{~J} / \mathrm{cm}^{2}$. The ultimate strength is almost doubled from $560 \mathrm{MPa}$ in the as-received state to $1050 \mathrm{MPa}$ after irradiation in xenon plasma.

\section{Conclusions}

The friction coefficient on the surface of the composite irradiated in plasmas of different inert gases is stable when the energy density and irradiation pulse duration of electron beam are changed. This is due to the stability of the structure in the top sublayer of the metal ceramic composite. As a result of pulsed electron irradiation in inert gas plasmas, a nanostructured heterogeneous structure is formed in the surface layer of $\mathrm{TiC}-(\mathrm{Ni}-\mathrm{Cr})$ metal ceramic alloy. The thickness of the modified layer increases when the atomic weight of a plasma gas is consequently increased from argon to krypton and xenon.

As the TiC particles size decreases, the value of friction coefficient on the irradiated surface decreases, while the bending strength increases when load is applied on the irradiated surface.

\section{References}

[1] K. Brookes, World Directory and Handbook of Hardmetals and Hard Materials, 6th edn. (International Carbide Data, Metal Powder Industry, Hertfordshire, 1996)

[2] P. Ettmayer, Hardmetals and cermets. Annu. Rev. Mater. Sci. 19, 145-164 (1989)

[3] P. Ettmayer, H. Kolaska, H.M. Ortner, History of hardmetals, in Comprehensive Hard Materials, vol. Vol. 1., ed. by V.K. Sarin, D. Mari, L. Llanes (Elsevier, Amsterdam, 2014), pp. 3-27

[4] A. Bose, Int. J. Powder Metall. 43(2), 17-19 (2007)

[5] J.A. Ghani, C.H.C. Haron, S.H. Hamdan, A.Y.M. Said, S.H. Tomadi, Ceram. Int. 39, 4449-4456 (2013)

[6] A.A. Vereschaka, S.N. Grigoriev, Wear 378, 43-57 (2017) 
[7] J.A. Ghani, C.H. Che Haron, M.S. Kasim, M.A. Sulaiman, S.H. Tomadi, J. Mater. Res. 31, 1873-1879 (2016)

[8] J.A. Arsecularatne, L.C. Zhang, C. Montross, Int. J. Mach. Tools Manuf 46, 482-491 (2006)

[9] S. Lay, J.M. Missiaen, Microstructure and morphology of hardmetals, in Comprehensive Hard Materials, vol. 1, ed. by V.K. Sarin, D. Mari, L. Llanes (Elsevier, Amsterdam, 2014), pp. $91-120$

[10] S.Z. Hao, Y. Zhang, Y. Xu, N. Gey, T. Grosdidier, C. Dong, Appl. Surf. Sci. B 285, 552-556 (2013)

[11] V.E. Ovcharenko, S.G. Psakhie, J. Mater. Sci. Technol. 21, 427-429 (2005)

[12] B. Yu, V.E. Ovcharenko, S.G. Psakhie, O.V. Lapshin, J. Mater. Sci. Technol. 22, 511-513 (2006)

[13] S. Psakhie, V. Ovcharenko, B.H. Yu, E. Shilko, S. Astafurov, Y. Ivanov, A. Byeli, A. Mokhovikov, J. Mater. Sci. Technol. 29, 1025-1034 (2013)
[14] V.E. Ovcharenko, A.A. Mokhovikov, A.S. Ignat'ev, Steel Transl. 43, 348-350 (2013)

[15] A.S. Ignatyev, A.A. Mokhovikov, V.E. Ovcharenko, Appl. Mech. Mater. 682, 530-536 (2014)

[16] V.E. Ovcharenko, S.G. Psaknye, Y.F. Ivanov, A.A. Mokhovikov, B. Yu, Y. Zhao, A.S. Ignat'ev, Rare Met Mater. Eng. 44, 1-6 (2015)

[17] N.N. Koval, Y.F. Ivanov, Russ. Phys. J. 56, 1150-1155 (2014)

[18] G.E. Ozur, S.A. Popov, V.F. Fedushchak, Russ. J. Appl. Phys. 53, 919-926 (2008)

[19] D.I. Proskurovsky, V.P. Rotshtein, G.E. Ozur, Y.F. Ivanov, A.B. Markov, Surf. Coat. Technol. 125, 49-56 (2000)

[20] D.I. Proskurovsky, V.P. Rotshtein, G.E. Ozur, A.B. Markov, D.S. Nazarov, J. Vac. Sci. Technol. A 16, 2480-2488 (1998)

[21] C. Dong, A. Wu, S. Hao, J. Zou, Z. Liu, P. Zhong, A. Zhang, T. $\mathrm{Xu}$, J. Chen, J. Xu, Q. Liu, Z. Zhou, Surf. Coat. Technol. 163-164(2), 620-624 (2003) 